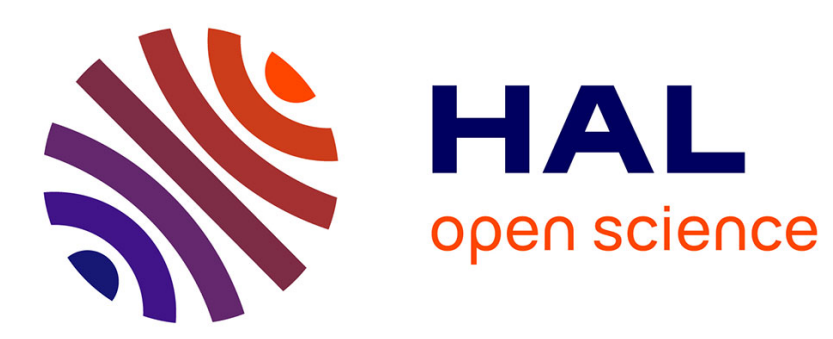

\title{
Enhanced fraction of coupled Er in silicon-rich silicon oxide layers grown by magnetron co-sputtering
}

\author{
K. Hijazi, L. Khomenkova, F. Gourbilleau, J. Cardin, R. Rizk
}

\section{To cite this version:}

K. Hijazi, L. Khomenkova, F. Gourbilleau, J. Cardin, R. Rizk. Enhanced fraction of coupled Er in silicon-rich silicon oxide layers grown by magnetron co-sputtering. Journal of Luminescence, 2009, 129 (12), pp.1886 - 1889. 10.1016/j.jlumin.2009.04.037 . hal-01622761

\section{HAL Id: hal-01622761 \\ https://hal.science/hal-01622761}

Submitted on 24 Oct 2017

HAL is a multi-disciplinary open access archive for the deposit and dissemination of scientific research documents, whether they are published or not. The documents may come from teaching and research institutions in France or abroad, or from public or private research centers.
L'archive ouverte pluridisciplinaire HAL, est destinée au dépôt et à la diffusion de documents scientifiques de niveau recherche, publiés ou non, émanant des établissements d'enseignement et de recherche français ou étrangers, des laboratoires publics ou privés. 


\title{
Enhanced fraction of coupled $\mathrm{Er}$ in silicon-rich silicon oxide layers grown by magnetron co-sputtering
}

\author{
K. Hijazi, L. Khomenkova, F. Gourbilleau, J. Cardin, R. Rizk* \\ CIMAP, UMR CNRS/CEA/ENSICAEN/UNIVERSITE DE CAEN, 6 Bd Maréchal Juin, F-14050 Caen Cedex, France
}

\begin{abstract}
A B S T R A C T
The structural and optical emission properties of Er-doped silicon-rich silica layers containing $10^{21} \mathrm{at} \mathrm{cm}^{-3}$ of erbium are studied as a function of deposition conditions and annealing treatment. Magnetron co-sputtering of three confocal targets $\left(\mathrm{Si}, \mathrm{SiO}_{2}\right.$ and $\left.\mathrm{Er}_{2} \mathrm{O}_{3}\right)$ under a plasma of pure argon was used to deposit the layers at $500{ }^{\circ} \mathrm{C}$. The silicon excess was varied in the layers in the range $7-15$ at $\%$ by monitoring the power applied on Si cathode. The as-grown samples were found significantly emitting at $1.54 \mu \mathrm{m}$ under non-resonant excitation. A maximum Er emission was observed after annealing at a moderate temperature $\left(600^{\circ} \mathrm{C}\right)$ for any amount of Si excess, with a highest $1.54 \mu \mathrm{m}$ photoluminescence $(\mathrm{PL})$ from the sample containing 13 at\% of Si. While no nanocrystals were observed in the samples annealed at $600^{\circ} \mathrm{C}$, the sensitizers might, therefore, consist in 'atomic' scaled entities (Si agglomerates, for example) considered in recent similar work. The comparison of the emission features of our "best" sample and their counterparts reported so far, shows that the approach used this work allows to increase the fraction of the $\mathrm{Er}^{3+}$ ions coupled to $\mathrm{Si}$ sensitizers from $3 \%$ up to $12 \%$ of the total $\mathrm{Er}$ content.
\end{abstract}

Infrared absorption

Refractive index

Magnetron sputtering

\section{Introduction}

A considerable effort is devoted since many years on siliconbased photonics [1] and, more particularly, on the use of Er ions $[2,3]$ as optical centers emitting at the standard telecommunication wavelength of $1.5 \mu \mathrm{m}$. As host materials for $\mathrm{Er}$, either crystalline Si (c-Si) or silica has shown specific drawbacks, such as the detrimental back transfer for c-Si [4] preventing any roomtemperature functionality and the low absorption cross section $\left(\sim 10^{-20}-10^{-21} \mathrm{~cm}^{2}\right)$ for $\mathrm{SiO}_{2}$ [5] requiring high-power resonant excitation. These problems have been overcome by the coexistence of Er ions with Si nanoclusters (Si-nc) within a silica matrix. Indeed, these Si-nc were found to induce an indirect excitation of Er [6] that allows an increase of the effective excitation cross section of Er ions by 3-4 orders of magnitude, while maintaining the absence of energy back transfer owing to the large bandgap of both silica and Si-nc [7,8]. The presence of Si-nc provides additional advantages such as the increase of the refractive index for better optical guiding and the improvement of both injection and transport of carriers for electrical excitation. On the other hand, it appeared that either crystalline or amorphous Si-nc are still sensitizers $[8,9]$, provided that their size is lower than about $4 \mathrm{~nm}[10]$ and their separating distance from the Er ions is lower than $0.5 \mathrm{~nm}[10,11]$. Such a very short interaction distance is

\footnotetext{
* Corresponding author

E-mail address: richard.rizk@ensicaen.fr (R. Rizk).
}

considered as being the main factor limiting the fraction of Er ions coupled to Si-nc to a few \% $[12,13]$. This situation requires, therefore, some nanoengineering of the material composition through the growth of a high density of very small Si-based sensitizer entities to maximize the fraction of coupled Er.

The present paper deals, therefore, with the optimization of such a material. Series of layers were grown by magnetron cosputtering and subsequently annealed before being submitted to various structural and optical characterizations. The effects of both and either Si excess and annealing treatment have been particularly examined.

\section{Experimental details}

The series of Er-doped silicon-rich silicon oxide (Er-SRSO) layers were deposited by magnetron co-sputtering of three confocal targets, $\mathrm{SiO}_{2}, \mathrm{Er}_{2} \mathrm{O}_{3}$ and $\mathrm{Si}$ under a plasma of pure argon. This novel approach used by our team differs from that used earlier when a unique $\mathrm{SiO}_{2}$ target topped by chips of $\mathrm{Er}_{2} \mathrm{O}_{3}$ is sputtered under a mixture of $\mathrm{Ar}+\mathrm{H}_{2}$ plasma $[8,11,13]$. The content of Er and Si excess can be finely and independently tuned through the monitoring of the RF power applied on each cathode. The total pressure in the chamber and the power density applied onto $\mathrm{SiO}_{2}$ and $\mathrm{Er}_{2} \mathrm{O}_{3}$ cathodes were fixed at $3 \mathrm{mTorr}, 7.4$ and $0.74 \mathrm{~W} / \mathrm{cm}^{2}$, respectively, while that on the $\mathrm{Si}$ target $\left(P_{\mathrm{Si}}^{R F}\right)$ was changed between 0.74 and $2.07 \mathrm{~W} \mathrm{~cm}^{-2}$. All samples were grown at a 
substrate temperature $T_{s}=500{ }^{\circ} \mathrm{C}$ on a rotating holder for good homogeneity of both thickness and composition. The deposited layers were subsequently annealed under a nitrogen flux for $1 \mathrm{~h}$ at different temperatures $T_{a}$ between $500^{\circ} \mathrm{C}$ and $900{ }^{\circ} \mathrm{C}$. The structural properties were investigated by Fourier transform infrared spectroscopy (FTIR) measurements performed under normal and Brewster $\left(65^{\circ}\right)$ incidence in the range $500-4000 \mathrm{~cm}^{-1}$, using a Nicolet Nexus spectrometer. The refractive index and the thickness of layer were obtained by M-lines measurements performed in reflection configuration [14-16], using a He-Ne laser emitting at $632.8 \mathrm{~nm}$ polarized in transverse electric (TE) mode. The optical properties were examined by photoluminescence (PL) measurements recorded with a nonresonant excitation $(476 \mathrm{~nm})$ line delivered by $\mathrm{an}^{\mathrm{Ar}^{+}}$laser, in order to ensure that Er was excited through the Si sensitizers. The Er PL was measured with a Jobin Yvon $1 \mathrm{~m}$ single grating monochromator and Northcoast Germanium detector cooled with liquid nitrogen. The PL signal was recorded through a SRS lock-in amplifier (SP830 DPS) referenced to the chopping frequency of light of $20 \mathrm{~Hz}$. The time-resolved Er PL was measured with the already described PL system, the signal being displayed by a Tektronix oscilloscope (TDS 3012B).

\section{Results and discussion}

The $\mathrm{Si}$ excess induced by the variation of $P_{\mathrm{Si}}^{R F}$ has been estimated from the evolution of the $\mathrm{TO}_{3}$ mode of the FTIR spectra recorded at normal incidence, as shown in Fig. 1, following the method described in Ref. [17]. Briefly summarized, this method is based on a linear relation between the shift of the $\mathrm{TO}_{3}$ peak position for a sub-stoichiometric $\mathrm{SiO}_{x}(1<x<2)$ matrix, with respect to that of sputtered $\mathrm{SiO}_{2}$, and the stoichiometric coefficient $x$. Fig. 1 shows a gradual shift of the $\mathrm{TO}_{3}$ peak position towards lower values of the wavenumber, when $\left(P_{\mathrm{Si}}^{R F}\right)$ is increased. This behaviour implies some proportionality between the oxidation degree of the matrix, or the coefficient $x$, and $P_{\mathrm{Si}}^{R F}$ responsible of the $\mathrm{Si}$ excess. Indeed, the $\mathrm{TO}_{3}$ peak shifts gradually from $1080 \mathrm{~cm}^{-1}$ for $P_{\mathrm{Si}}^{R F}=0$ (silica film free of $\mathrm{Si}$ excess) to $1062 \mathrm{~cm}^{-1}$ for the sub-stoichiometric layer grown with
$2.07 \mathrm{~W} \mathrm{~cm}^{-2}$. The estimated $\mathrm{Si}$ excess was found to increase from about 7 at\% to nearly 15 at\% when the $P_{S i}^{R F}$ was increased from 0.74 to $2.07 \mathrm{~W} \mathrm{~cm}^{-2}$, as shown in the inset of Fig. 1 . Such an increase is corroborated by the evolution of the refractive index shown in the same inset, and which increases with $P_{\mathrm{Si}}^{R F}$ from 1.489 to 1.646 , as deduced from M-lines measurements.

Since the samples should contain the optimum concentration of emitting centers, we have incorporated an Er content as high as $10^{21} \mathrm{~cm}^{-3}$ which appears higher than the threshold value $\left(\sim 2 \times 10^{20} \mathrm{~cm}^{-3}\right)$ preventing up-conversion phenomena [18]. However, such detrimental phenomena can be minimized when using moderate values of excitation flux $\varphi\left(10^{18}-10^{19} \mathrm{ph} \mathrm{cm}^{-2}\right.$ $\mathrm{s}^{-1}$ ). Indeed, the typical evolution of the PL intensity at $1.54 \mu \mathrm{m}$ vs $\varphi$, displayed in Fig. 2 for both as-deposited and annealed (at $600^{\circ} \mathrm{C}$ ) samples, shows an almost linear behaviour that is indicative of limited effects of up-conversion phenomena and concentration quenching. To note that the emission observed from

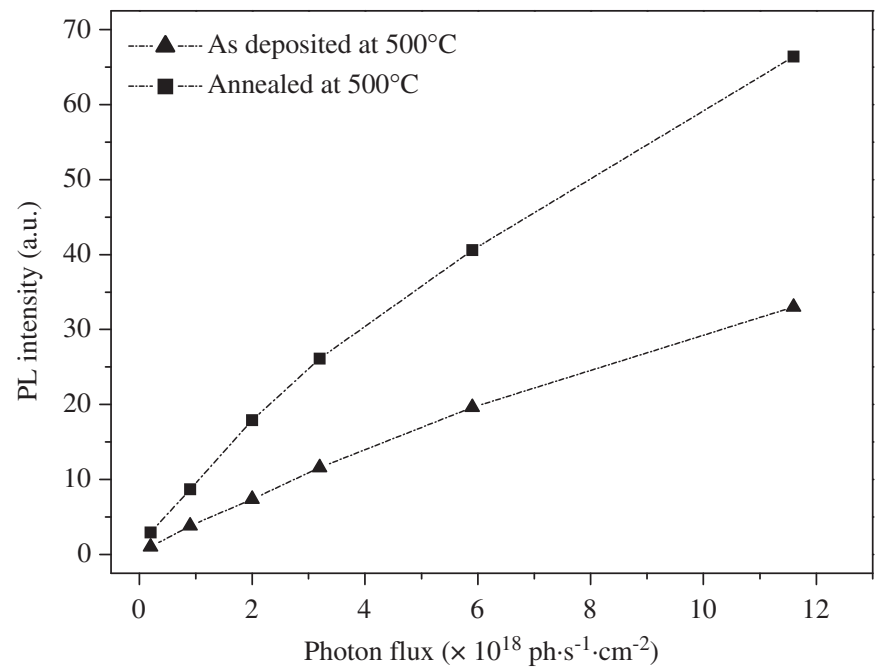

Fig. 2. Variation of the PL intensity at $1.54 \mu \mathrm{m}$ for the as-deposited and annealed samples as a function of the photon flux of the non-resonant excitation line $476 \mathrm{~nm}$.

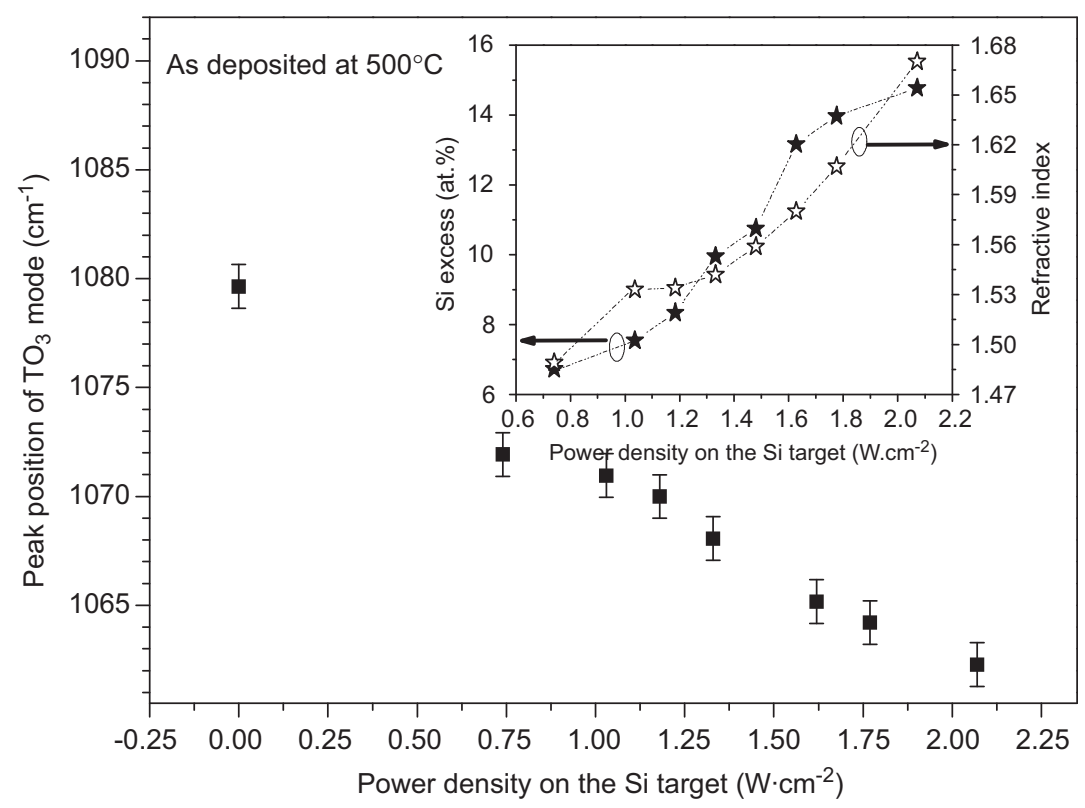

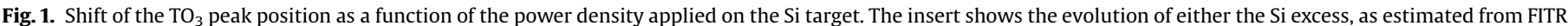
spectra, and of the refractive index, as determined by M-lines, in function of the power density applied on the Si target. 
the as-grown samples is likely originated from the formation of Si-based sensitizers during the growth process. The annealing at relatively low temperature $\left(600^{\circ} \mathrm{C}\right)$ improves the emission by a factor 2, probably due to the formation of additional sensitizers together with the expected improvement of the matrix.

Fig. 3a shows the effect of the annealing temperature $T_{a}$ on the evolution of the Er PL for various values of the Si excess. The general trend is almost similar for all values of Si excess: a first slight increase up to a maximum for $T_{a}=600^{\circ} \mathrm{C}$, followed by a gradual decrease for higher values of $T_{a}$. This evolution is hardly observable for the lowest values of Si excess (7.5-8.3 at\%), but it is the most pronounced for 13 at\% of Si excess. To note that the level of PL increases with the Si excess, all along the $T_{a}$ range, reaches a maximum for 13 at\% that appears as the optimum value for the best emission and then decreases for the highest value of 14.7 at\%. Such a result might indicate that, for any $T_{a}$ value, the highest coupling between $\mathrm{Er}$ ions and Si-based sensitizers takes place for 13 at\% of Si excess. Concerning the evolution of the PL level against the Si excess, one may suggest the following: (i) the first increase of $\mathrm{Si}$ excess is expected to enhance the density of Si-nc sensitizers until probably saturating the available seeds (for a given $T_{a}$ ) which seems to occur for 13 at\% of Si excess; (ii) further increase of $\mathrm{Si}$ excess, from 13 to 14.7 at\%, might lead to increasing the average size of the formed Si-nc at the expense of their density and then of their coupling with $\mathrm{Er}$ ions. Anyway, these Si-nc are all
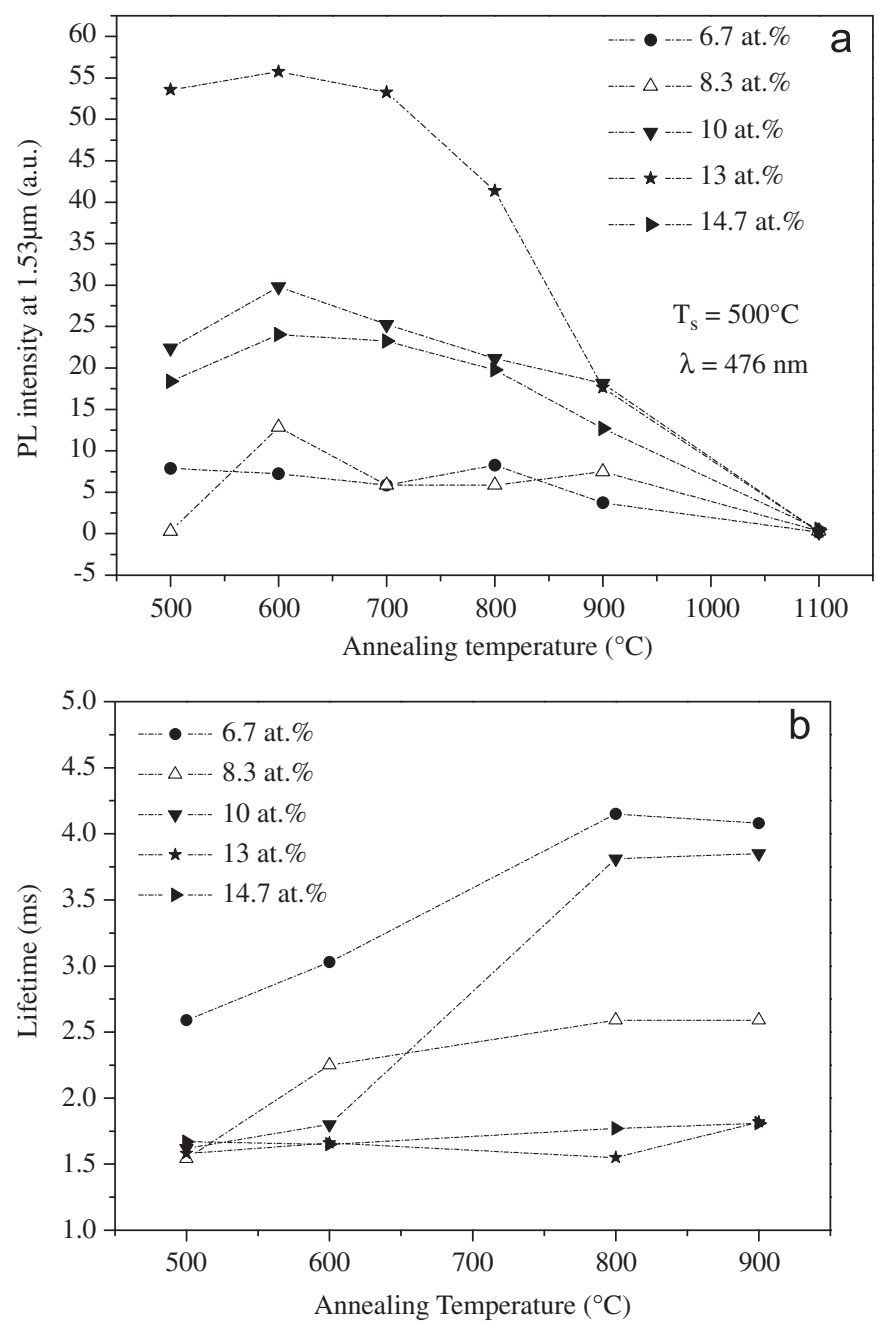

Fig. 3. (a) Variation of the PL intensity at $1.54 \mu \mathrm{m}$ for the annealed samples containing the indicated values of $\mathrm{Si}$ excess, as a function of annealing temperature $T_{a}$. The samples were excited with the non-resonant line $(476 \mathrm{~nm})$. (b) Evolution of the corresponding emission lifetime against the annealing temperature $T_{a}$. amorphous, since $T_{a} \leqslant 900^{\circ} \mathrm{C}$ and then hardly observable by transmission electron microscopy. The emission lifetime $\tau_{P L}$ is generally increased when $T_{a}$ is raised, even though this improvement is very limited, if not absent, for the highest values of $\mathrm{Si}$ excess with $1.5 \mathrm{~ms}<\tau_{P L}<2 \mathrm{~ms}$, as shown in Fig. $3 \mathrm{~b}$.

The most significant feature concerns the notable emission observed from the non-annealed sample grown at $500{ }^{\circ} \mathrm{C}$ (Fig. 2) and the maximum PL recorded after annealing at moderate temperature, $T_{a}=600^{\circ} \mathrm{C}$ (Fig. 3a), for which no 'large' Si-nc might form. These two observations are both indicative of the production of some Si-based entities (agglomerates of atoms, for example) that play the role of sensitizers. These entities might be compared to the 'atomic' scaled sensitizers that have been suspected to form at the same moderate temperature $\left(600^{\circ} \mathrm{C}\right)$ in similarly sputtered samples [19]. The 'atomic' scaled sensitizers should be dense enough to ensure a high coupling and this could explain the significant PL observed from our as-grown samples, as well as the maximum emission detected after annealing at only $600^{\circ} \mathrm{C}$. To attempt a rough estimate of the proportion of $\mathrm{Er}$ ions coupled to Si sensitizers, we compare in Fig. 4, the Er PL spectra of our best sample (13 at\% of Si excess) recorded before and after annealing at $600^{\circ} \mathrm{C}$ with the PL spectrum of the best sample obtained earlier with the sputtering of a silica target topped by $\mathrm{Er}_{2} \mathrm{O}_{3}$ chips $[8,11,13]$. This latter is considered here as a reference, was annealed at $900^{\circ} \mathrm{C}$ and contains, however, lower Er content $\left(5 \times 10^{20} \mathrm{at} \mathrm{cm}^{-3}\right)$ and $\mathrm{Si}$ excess ( $\left.7 \mathrm{at} \%\right)$. Among the $\mathrm{Er}$ ions contained in the reference sample, only $3 \%$ were found coupled to sensitizers [13], i.e. $\sim 1.5 \times 10^{19} \mathrm{~cm}^{-3}$. As the spectra of Fig. 4 were recorded with the same photon flux $\left(\sim 10^{19} \mathrm{ph} \mathrm{cm}^{-2} \mathrm{~s}^{-1}\right)$, we assume that the intensity (normalized to the excited volume of the sample) $I_{P L} \propto \sigma_{\text {eff }} N_{E r, c} \tau_{P L} / \tau_{R A D}$, where $\sigma_{\text {eff }}$ is the effective excitation cross section, $\tau_{P L}$ is the measured lifetime, $N_{E r, c}$ the concentration of $\mathrm{Er}^{3+}$ ions coupled to Si-nc, which is equal to about $1.5 \times 10^{19} \mathrm{~cm}^{-3}$ for the reference sample.

By comparing the $I_{P L}$ of the reference to that of our present layer (3.7 times higher), the values of their $\tau_{\text {decay }}(4.5 \mathrm{vs} 1.5 \mathrm{~ms}$ ), the values of their $\tau_{\text {rad }}$ which is $\propto n^{2}$ ( $n$ is the refractive index and is equal to 1.52 for the reference and 1.56 for the examined sample), as can be deduced from Ref. [20] ( 9 vs $12 \mathrm{~ms}$ ), and the ratio of their $\sigma_{\text {eff }}\left(5-6 \times 10^{-18} \mathrm{vs} \sim 10^{-17} \mathrm{~cm}^{-2}\right)$, one could estimate $N_{E r, c}$ for our best sample to about $1.2 \times 10^{20} \mathrm{~cm}^{-3}$. This value represents nearly $12 \%$ of the total Er content $\left(\sim 10^{21} \mathrm{~cm}^{-3}\right)$ and might correspond to higher percentage of the optically active $\mathrm{Er}$

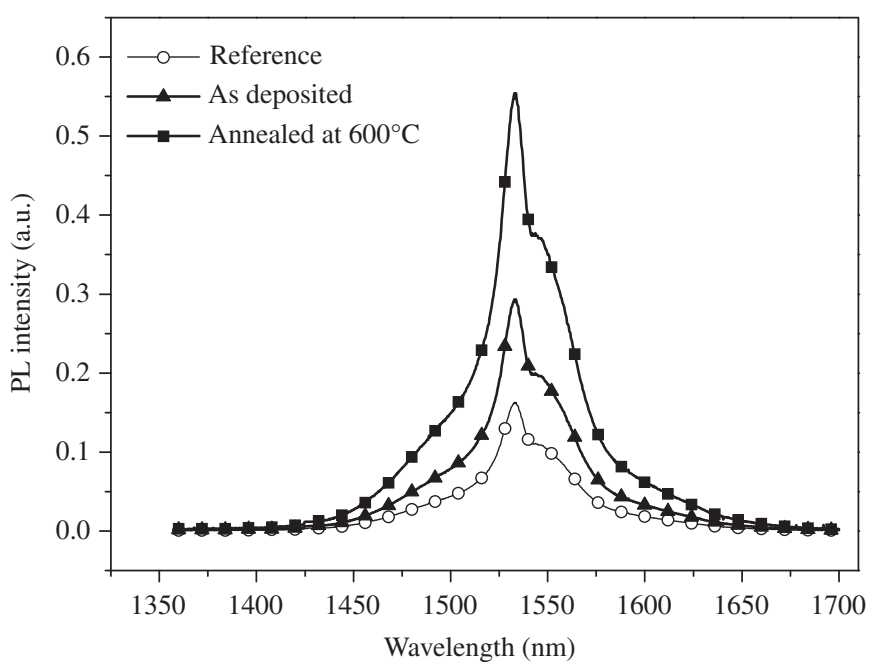

Fig. 4. Comparison of the PL spectra recorded on the best sample of Fig. 3 (13 at\% $\mathrm{Si}$ excess, annealed at $\left.600^{\circ} \mathrm{C}\right)$ to those of the as-grown sample and the best sample described in Ref. [13][ (Si excess: 7 at\%, Er content: $5.4 \times 10^{20} \mathrm{at} \mathrm{cm}^{-3}$, annealing temperature: $900^{\circ} \mathrm{C}$ ). The samples were excited with the non-resonant line $(476 \mathrm{~nm})$ and a flux of $\sim 10^{19} \mathrm{ph} \mathrm{cm}^{-2} \mathrm{~s}^{-1}$. 
ions. Considering the relatively high value of $\mathrm{Er}$ content $\left(\sim 10^{21}\right.$ $\mathrm{cm}^{-3}$ ), one should be cautious concerning the concentrationrelated detrimental effects (up-conversion, concentration quenching, ... ) as for their impact on the improvement of the coupled fraction of Er. There is an ongoing work on lower Er content (few $10^{20} \mathrm{~cm}^{-3}$ ) for further optimization of the material which is necessary to couple the majority of the optically active Er ions and minimize the losses for the achievement of a net gain.

\section{Conclusion}

In conclusion, the effects of both $T_{a}$ and $\mathrm{Si}$ excess have been examined with the aim of improving the fraction of Er coupled to $\mathrm{Si}$-nc sensitizers. While the as-grown samples at $500^{\circ} \mathrm{C}$ were found significantly emitting, the highest emission was detected from the samples containing 13 at\% of Si excess and annealed at $T_{a}=600^{\circ} \mathrm{C}$. Such a behaviour with a non-resonant excitation $(476 \mathrm{~nm})$ is ascribed to the sensitizing effects of some 'atomic' scaled entities formed at relatively moderate temperature $\left(500-600^{\circ} \mathrm{C}\right)$. A rough estimate of the fraction of coupled $\mathrm{Er}$ has allowed to notice that their proportion was improved from about $3 \%$ for earlier samples to nearly $12 \%$. Further optimization of the material is still needed, together with processing at moderate temperature, for achieving an amplification silica medium with Er-coupled to Si-based sensitizers.

\section{Acknowledgments}

This work is supported by the European Community through the LANCER Project (FP6-IST 033574).

\section{References}

[1] L. Dal Negro, P. Fauchet, F. Iacona, M. Fujii, R. Rizk (Eds.), E-MRS Proceedings Symposium on Frontiers in Si-based Photonics, [Physica E (2008)].

[2] N. Daldosso, D. Navarro-Urrios, M. Melchiorri, C. García, P. Pellegrino, B. Garrido, C. Sada, G. Battaglin, F. Gourbilleau, R. Rizk, L. Pavesi, IEEE J. Sel. Top. Quantum Electron. 12 (2006) 1607.

[3] T. Gregorkiewicz, B.A. Andreev, M. Forcales, I. Izeddin, W. Jantsch, Z.F. Krasil'nik, D.I. Kryzhkov, V.P. Kuznetsov, J.M. Zavada, IEEE J. Sel. Top. Quantum Electron. 12 (2006) 1539.

[4] F. Priolo, G. Franzò, S. Coffa, A. Carnera, Phys. Rev. B 57 (1998) 4443.

[5] W. Miniscalco, in: M. Digonnet (Ed.), Rare-Earth-Doped Fiber Lasers and Amplifiers, Dekker, New York, 2001, p. 62.

[6] M. Fujii, M. Yoshida, Y. Kanzawa, S. Hayashi, K. Yamamoto, Appl. Phys. Lett. 71 (1997) 1198.

[7] F. Priolo, G. Franzò, D. Pacifici, V. Vinciguerra, F. Iacona, A. Irrera, J. Appl. Phys, 89 (2001) 264.

[8] F. Gourbilleau, L. Levalois, C. Dufour, J. Vicens, R. Rizk, J. Appl. Phys. 95 (2004) 3717.

[9] G. Franzò, S. Boninelli, D. Pacifici, F. Priolo, F. Iacona, C. Bongiorno, Appl. Phys. Lett. 82 (2003) 3871.

[10] J.H. Jhe, J.H. Shin, K.J. Kim, D.W. Moon, Appl. Phys. Lett. 82 (2003) 868.

[11] F. Gourbilleau, R. Madelon, C. Dufour, R. Rizk, Opt. Mater. (Amsterdam, Neth.) 27 (2005) 868.

[12] M. Wojdak, M. Klik, M. Forcales, O.B. Gusev, T. Gregorkiewicz, D. Pacifici, G. Franzò, F. Priolo, F. Iacona, Phys. Rev. B 69 (2004) 233315.

[13] B. Garrido, C. García, S.-Y. Seo, P. Pellegrino, D. Navarro-Urrios, N. Daldosso, L. Pavesi, F. Gourbilleau, R. Rizk, Phys. Rev. B 76 (2007) 245308.

[14] R.T.H. Kersten, J. Mod. Opt. 22 (1975) 503.

[15] R. Ulrich, R. Torge, Appl. Opt. 12 (1973) 2901.

[16] J. Cardin, D. Leduc, Appl. Opt. 47 (2008) 894.

[17] P.G. Pai, S.S. Chao, Y. Takagi, G. Lucovsky, J. Vac. Sci. Technol. A 4 (1986) 689; N. Tomozeiu, Appl. Surf. Sci. 25 (2006) 376.

[18] D. Pacifici, G. Franzò, F. Priolo, F. Iacona, L. Dal Negro, Phys. Rev. B 67 (2003) 245301.

[19] O. Savchyn, F.R. Ruhge, P. Kik, R.M. Todi, K.R. Coffey, H. Nukala, H. Heinrich, Phys. Rev. B 76 (2007) 195419.

[20] N. Daldosso, D. Navarro-Urrios, M. Melchiorri, L. Pavesi, C. Sada, F. Gourbilleau, R. Rizk, Appl. Phys. Lett. 88 (2006) 16190. 